Document downloaded from:

http://hdl.handle.net/10251/150622

This paper must be cited as:

Vicente, C.; Wolk, D.; Hartnagel, H.; Gimeno, B.; Boria Esbert, VE.; Raboso, D. (2007). Experimental analysis of passive intermodulation at waveguide flange bolted connections. IEEE Transactions on Microwave Theory and Techniques. 55(5):1018-1028. https://doi.org/10.1109/TMTT.2007.895400

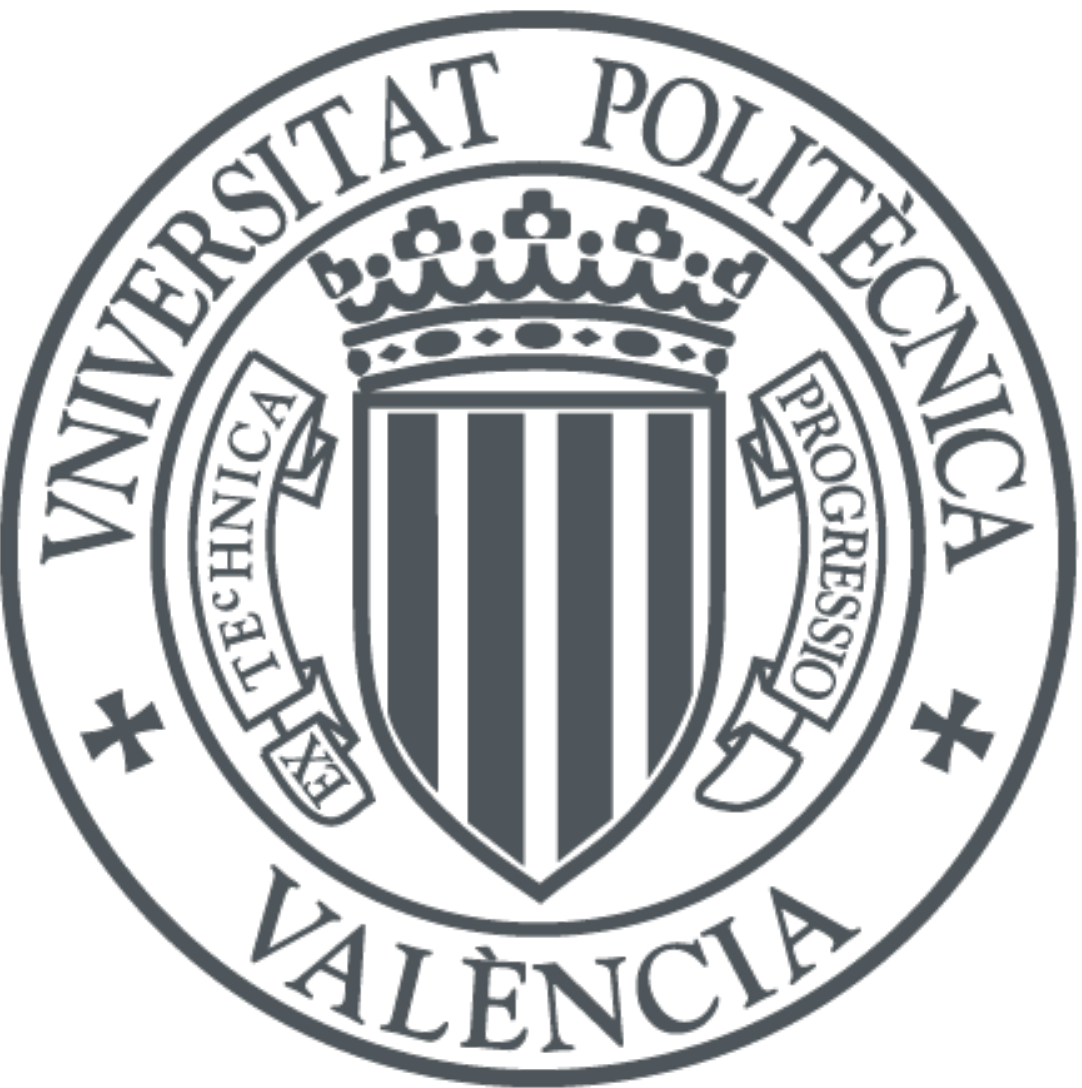

The final publication is available at

https://doi.org/10.1109/TMTT.2007.895400

Copyright Institute of Electrical and Electronics Engineers

Additional Information 


\title{
Experimental Analysis of Passive Intermodulation at Waveguide Flange Bolted Connections
}

\author{
Carlos Vicente, Dieter Wolk, Hans L. Hartnagel, Life Fellow, IEEE, Benito Gimeno, Member, IEEE, \\ Vicente E. Boria, Senior Member, IEEE, and David Raboso
}

\begin{abstract}
In this paper, the generation of passive intermodulation at rectangular waveguide flange bolted connections is investigated. An exhaustive series of tests has been performed in order to provide understanding on the physics lying behind such a phenomenon. In particular, the intermodulation response of the system has been studied as a function of the applied torque to the flange screws. It has been found that, in some situations, the intermodulation response differs from its expected behavior. An interpretation of such discrepancies is given, and practical guidelines for the design of waveguide flanges free of passive intermodulation are provided as well.
\end{abstract}

Index Terms-Intermodulation distortion, intermodulation level, nonlinear systems, waveguide junctions.

\section{INTRODUCTION}

$\mathbf{P}$ ASSIVE intermodulation [1]-[3] presents an increasing risk for future satellite missions in which output power level, bandwidth, number of channels, and component dimensions are being driven to further limits. Despite being wellknown for years, it still represents a critical issue for designers due to its erratic behavior and to the lack of confident theoretical analysis. As a consequence, the design of the device follows some general rules (see, e.g., [1]), which do not generally ensure the best quality in the intermodulation response of a particular system. This always makes it necessary to carry out a huge amount of laboratory tests, which are extremely time ffconsuming.

Manuscript received November 3, 2006. This work was supported by the European Space Agency under the Surface Treat-ment and Coating for the Reduction of Multipactor and Passive Intermodula-tion Effects in RF Components Project, by the European Space Research and Technology Centre under Contract 17025/03/NL/EC, by the Generalitat Va-lenciana (Spain) under PREDECTOR Project IIARC0/2004/020, and by the Spanish Government (MEC) under a Juan de la Cierva Program Fellowship.

C. Vicente is with the Departamento de Comunicaciones, Universidad Politécnica de Valencia, E-46022 Valencia, Spain (e-mail: carlos.vicente@ uv.es).

D. Wolk is with Tesat-Spacecom GmbH \& Co. KG, D-71522 Backnang, Germany (e-mail: dieter.wolk@tesat.de).

H. L. Hartnagel is with the Institut für Hochfrequenztechnik, Technical University Darmstadt, D-64283 Darmstadt, Germany (e-mail: hartnagel@ hf.tudarmstadt.de).

B. Gimeno is with the Departamento de Física Aplicada y Electromagnetismo, Instituto de Ciencia de Materiales, Universidad de Valencia, E-46100 Burjasot (Valencia), Spain (e-mail: benito.gimeno@uv.es).

V. E. Boria is with the Departamento de Comunicaciones, Universidad Politécnica de Valencia, E-46022 Valencia, Spain (e-mail: vboria@ dcom.upv.es).

D. Raboso is with the Payloads Systems Division, European Space Agency, 2200-AG Noordwijk, The Netherlands (e-mail: david.raboso@esa.int).
Passive intermodulation originates due to the existence of a nonlinear component in the system, which generates harmonics of the input signal. If, additionally, more than one signal is present, intermodulation products are also excited. These new frequencies originated in the transmission band of the satellite can fall in the reception band. Despite the fact that these excited signals have low power (since they have been originated by passive components), the receive carriers are also low-power signals and, therefore, interference can occur.

Many passive intermodulation sources have been identified along the years [4], [5]. For instance, it has been found [6] that waveguide flange connections can result in high intermodulation levels due to the surface irregularities and to the native contaminant layer (mainly oxides) on the metallic surfaces [7]-[11]. Its mitigation, both in the test setup and flight hardware, commonly becomes hard to achieve because extremely low intermodulation levels (as low as $-140 \mathrm{dBm}$ ) can be relevant.

In this study, an experimental investigation has been performed to quantify intermodulation levels generated at aluminum and silver-plated aluminum waveguide flange bolted junctions in terms of the applied torque to the flange screws. This paper extends the work presented in [12] to the case of silver-plated aluminum waveguides and to the use of gaskets for the reduction of intermodulation levels.

\section{EXPERIMENTAL CONSIDERATIONS}

The input signal frequencies used for the measurements presented below were

$$
f_{1}=11.21 \mathrm{GHz} \quad f_{2}=11.895 \mathrm{GHz}
$$

with the third-order intermodulation product falling in the upper side of the spectrum being measured, i.e.,

$$
f_{\text {int }}=2 \cdot f_{2}-f_{1}=12.580 \mathrm{GHz} .
$$

\section{A. Samples}

The waveguides employed to perform the tests were pure aluminum ( $>99.9 \%$ purity) and silver-plated aluminum WR-90 waveguides $(22.86 \times 10.16 \mathrm{~mm})$. The silver coating was around $10-\mu \mathrm{m}$ thick. Aluminum as the base material and silver as the coating were chosen because they are the most representative waveguide materials for space applications.

As can be seen in Fig. 1, the waveguides had two different flanges. One of them was the flange under test (six screw holes), whereas the other one (eight screw holes) was the interface with the test setup. The latter should not add more intermodulation 


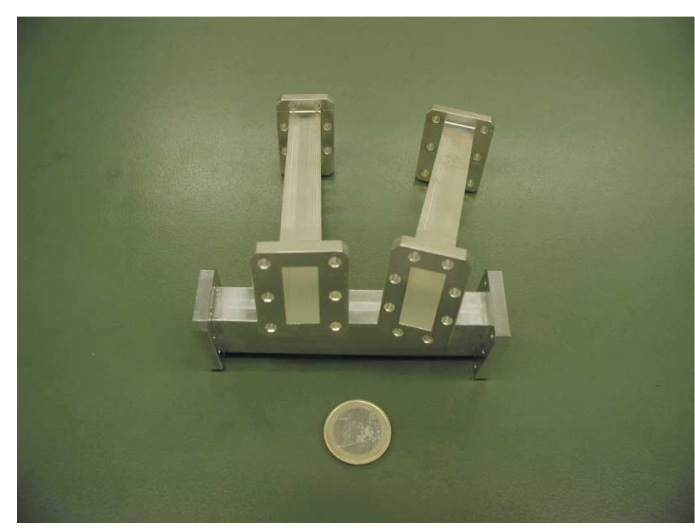

Fig. 1. Waveguides used. The flange under test (six holes) and the interface flange (eight holes) with the test setup are shown.

level to the noise floor. This is the reason why an eight-hole flange configuration was used and the waveguides were joined to the test setup interface flanges with the maximum possible torque ( $80 \mathrm{~N} / \mathrm{cm}$ for M3 (3-mm diameter) screws). On the other hand, the flange under test was a six-hole flange instead of the standard one (four holes) to minimize mechanical instabilities.

Apart from the pure waveguide-to-waveguide junction, gaskets were inserted between them in order to investigate their impact on the intermodulation response of the connection. The gaskets employed were made of aluminum, 3-mm thick and with two configurations: completely flat or bridged (with a 1-mm raised lip around the waveguide cavity, and on the outer border, in order to improve the contact pressure in the RF path region). The photographs and design of these gaskets are shown in Figs. 2 and 3.

All surfaces presented a finishing of around $0.4 \mu \mathrm{m}$. No further polishing was done in order to measure intermodulation levels of typical engineering surfaces.

The torque applied to the bolts was measured by means of calibrated screwdrivers, which provided a precision below 5\% for the range of the torque levels applied. The torque was always applied to the screws following a zig-zag pattern.

\section{B. Test Setup}

The achievement of an excellent test setup in intermodulation measurements is crucial due to the extremely high sensitivity that must be reached. The setup used provided a noise floor level of around $-145 \mathrm{dBm}$ for an input power of $170 \mathrm{~W}$ per carrier. The schematic of the test setup, which is described in the following, is shown in Fig. 4.

The test power for both carriers was generated by synthesizers $(1,2)$ and power amplifiers $(3,4)$. Low-pass filters $(7,8)$ were installed in order to suppress the harmonics coming from the amplifiers. Isolators $(5,6)$ were used to avoid any reflected signal reaching the amplifiers. Filters $(9,10)$ were selected to reduce the noise coming from the amplifiers at the frequency of the intermodulation product to be measured (around $-55-\mathrm{dB}$ rejection). The power of both carriers was measured by means of power meters $(15,16)$. They were adjusted to display the power at the output of the low-pass filter (18) after considering losses and the coupling factor of the couplers. Both carriers were

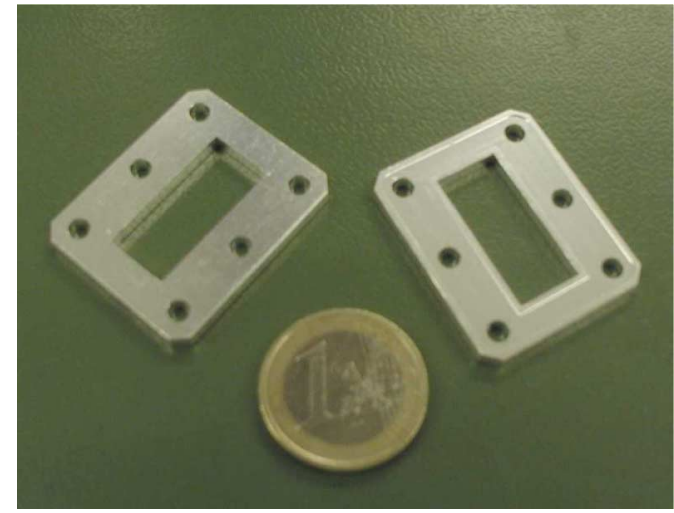

Fig. 2. Gaskets employed. (left) Flat gasket. (right) High-pressure ("bridged") gasket.

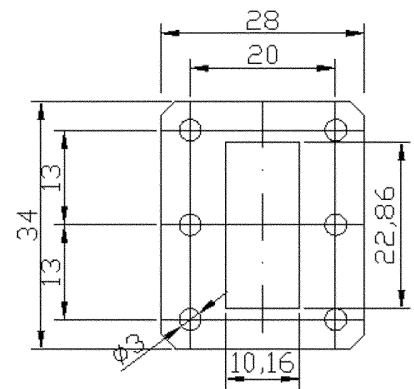

(a)

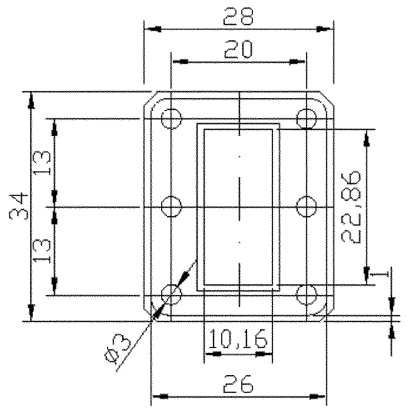

(b)
Fig. 3. Dimensions (in millimeters) of the gaskets used. The waveguide flanges have the same dimensions. (a) Flat gasket. (b) Bridged gasket.

combined by means of the transmit diplexer (17). The rejection between channels of this diplexer at the input frequencies was around $-55 \mathrm{~dB}$. A low-pass filter (18) was used to suppress potential intermodulation (rejection at the intermodulation frequency around $-70 \mathrm{~dB}$ ) generated in front of the device-under-test (DUT). The intermodulation product was separated from the carriers with the receive diplexer (20). Additional suppression of the carriers was reached by means of a low-pass filter (23). A low-pass filter (21) was used to suppress the intermodulation (rejection around $-70 \mathrm{~dB}$ ) generated in the high-power load (22).

To measure the exact intermodulation product level at the output of the DUT, the detection unit was calibrated at the selected intermodulation frequency. This involved the measurement of the loss/amplification of the path from the output port of the DUT up to the input port of the spectrum analyzer. Since a low-noise amplifier (25) was inside this chain, an attenuator (24) was installed in front of the input detection path to avoid the overdrive of the amplifier or the input of the network analyzer. The value of the attenuator was measured in advance and then taken into account in the measurement result. The loss/amplification measured this way was entered as a reference level offset into the spectrum analyzer so that the display showed the intermodulation level at the output port of the DUT. This calibration was performed for several values of the variable attenuator. 


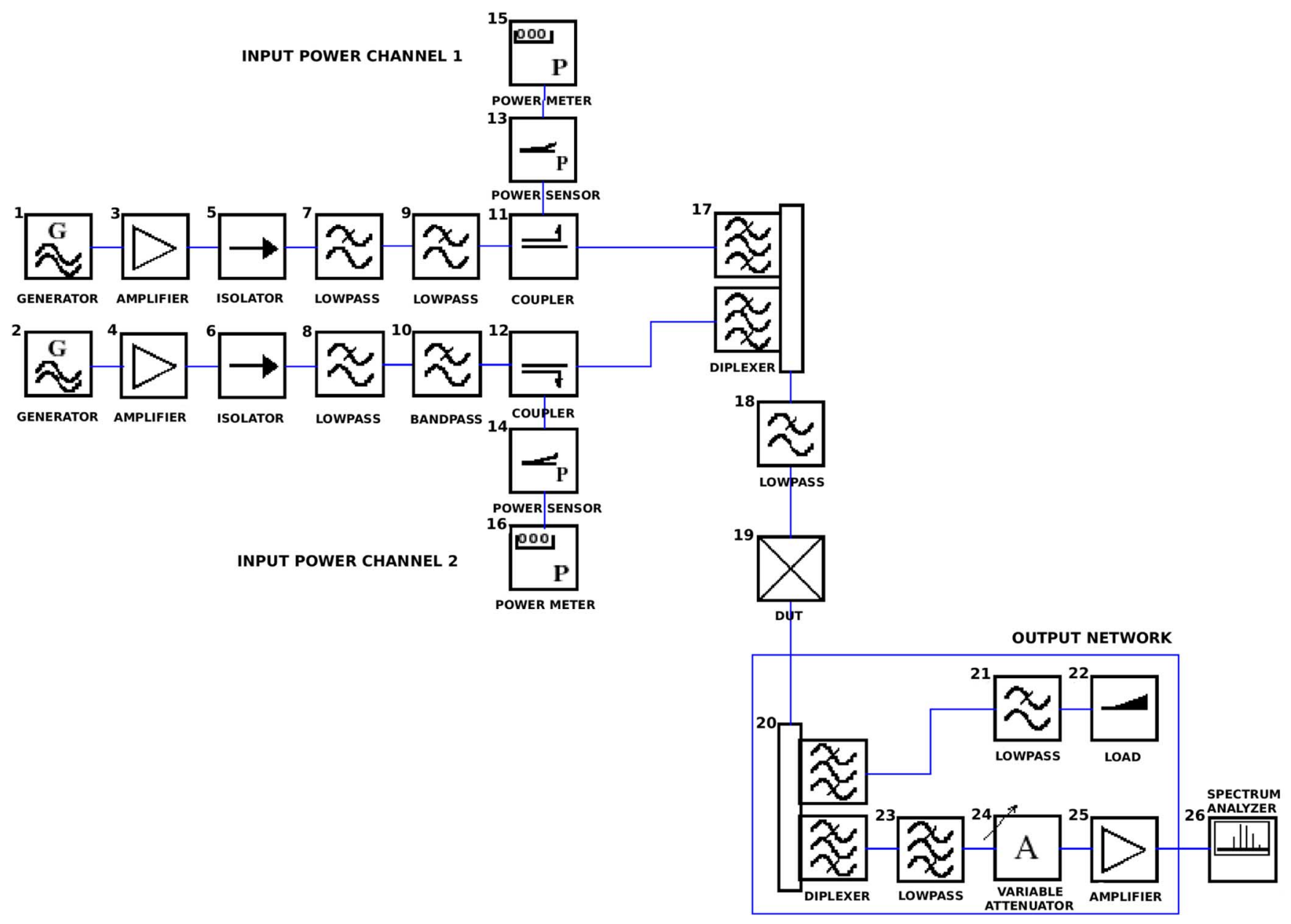

Fig. 4. Passive intermodulation test setup.

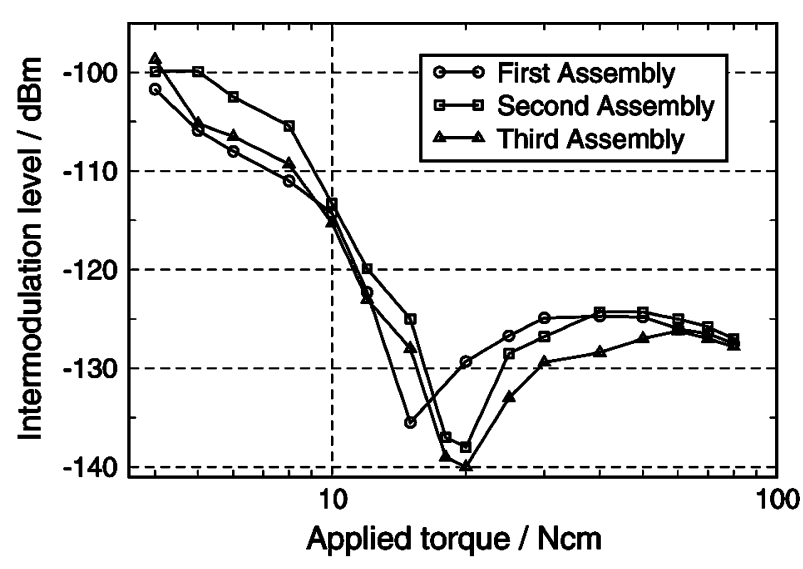

Fig. 5. Passive intermodulation level versus the applied torque to the screws for a combination of two $\mathrm{Al}$ waveguides. The measurements were repeated three times. Input combined power of $P=60 \mathrm{~W}$. Extracted from [12].

\section{Aluminum WaVEGUIDES}

The intermodulation response of several aluminum waveguides was investigated in [12]. Fig. 5 shows one of the results presented in that study.

The main conclusions of [12], as far as the intermodulation level as a function of the applied torque is concerned, are as follows.
1) Repeatability in the intermodulation level among different measurements was caused by the low average contact pressure reached between the waveguide flanges.

2) The intermodulation level decreases very steeply in the low torque range due to large-scale irregularities of the surfaces.

3) The existence of an intermodulation valley indicates a change of the physical sources responsible for intermodulation generation. At low mechanical loads, intermodulation sources are basically located at the void regions between the metals, whereas at high pressures, the intermodulation sources are located in the metal-to-metal contacts usually separated by a contaminant (dielectric) layer.

\section{A. Gaskets}

Gaskets were inserted between the aluminum waveguides whose intermodulation response is presented in Fig. 5. Both pure and silver-plated $\mathrm{Al}$ gaskets were tested. Three type of measurements were performed: inserting one flat gasket, using one bridged gasket, and employing two flat gaskets together. After this, measurements were carried out without any gasket at all in order to check if the performance of the measurements was affecting the intermodulation response of the connection. 


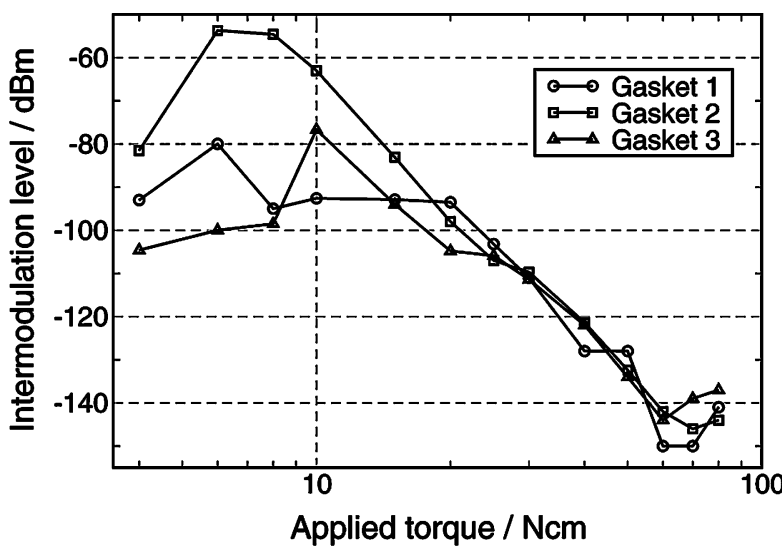

(a)

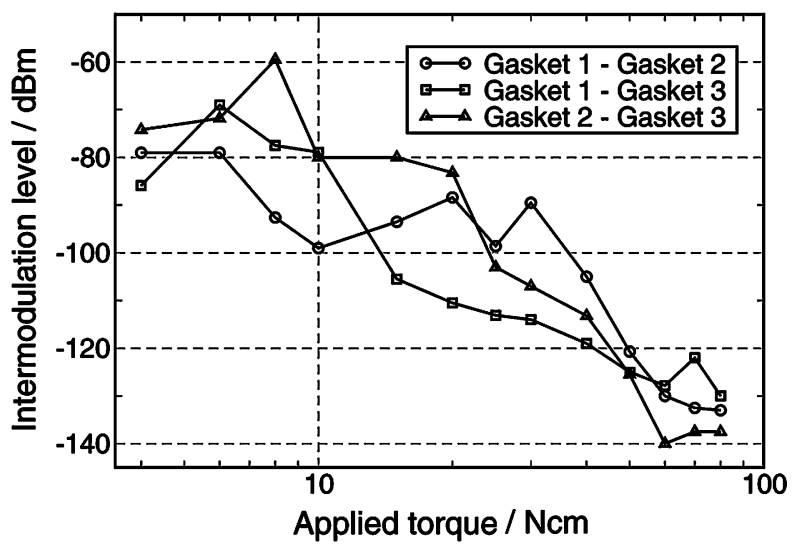

(c)

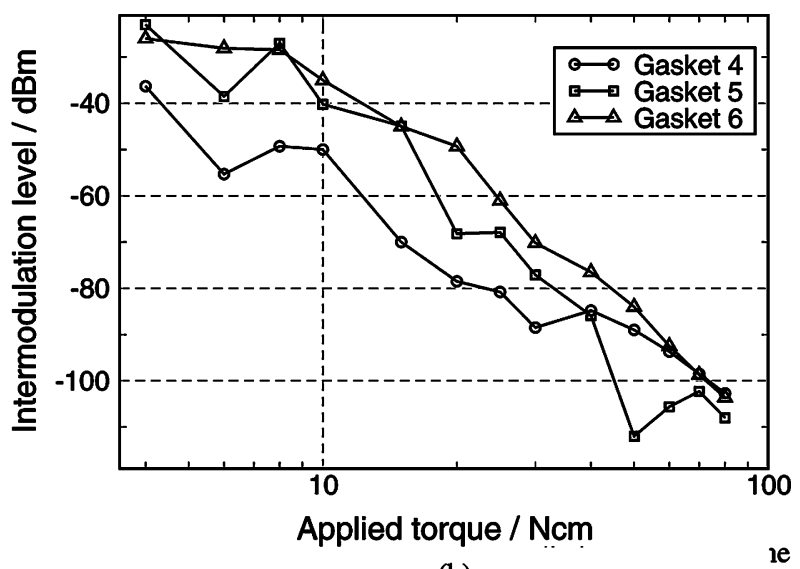

(b)

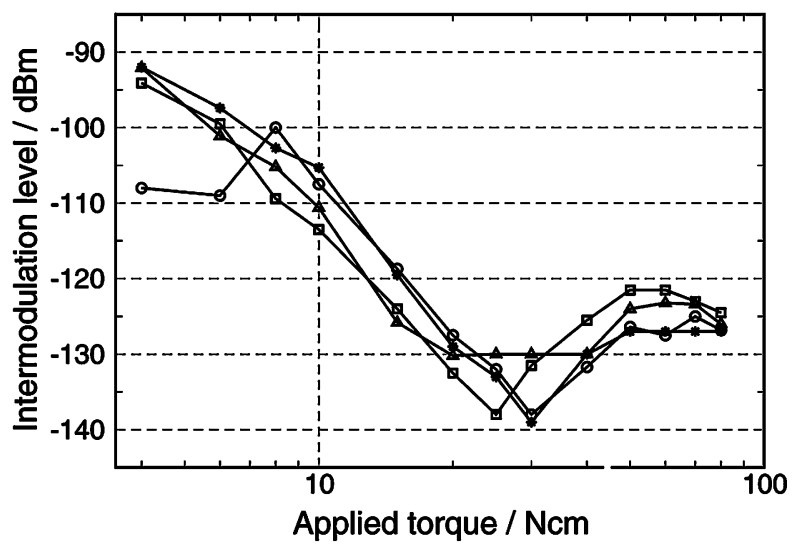

(d)

Fig. 6. Effect of inserting aluminum gaskets at the connection between two rectangular aluminum waveguides, $P=60$ W. Gaskets numbered " 1 ," " 2 ," and "3" are flat, whereas gaskets " 4 ," "5," and "6" are "bridged." (a) Passive intermodulation level versus applied torque when one flat gasket is inserted. (b) Passive intermodulation level versus applied torque when one "bridged" gasket is inserted. (c) Passive intermodulation level versus applied torque when two flat gaskets are inserted. (d) Passive intermodulation level versus applied torque without gaskets after the insertion of aluminum gaskets (four tests).

All the measurements were performed at a combined input power of $P=60 \mathrm{~W}$.

1) Aluminum Gaskets: For these gaskets, the results are shown in Fig. 6. It is observed that the use of gaskets led to an overall increase of the intermodulation level at low torques [see Fig. 6(a)]. In fact, at this torque range, the intermodulation response was quite unstable because two junctions (three in the case of two gaskets) were present and, thus, the surfaces barely deformed. However, at high torques, the intermodulation level decreased when using flat gaskets [one or two, as shown in Fig. 6(a) and (c)]. In principle, this behavior is unexpected since each additional metallic junction should rise the intermodulation level (an increase of $3 \mathrm{~dB}$ per extra connection should be observed, assuming that each connection has the same contribution).

To understand this, there are three main mechanical effects to be considered as follows, which occur when the gasket is inserted between the flanges.

- Increase of the elasticity of the connection, which is related to the ability of the gasket to be deformed in order to adapt itself to the waveguide flange surface imperfections [13]. This improves the seal of the junction on the whole flange surface resulting in a decrease of the intermodulation level excited. However, due to the relatively large thickness of the gasket $(3 \mathrm{~mm})$, it is not expected that this effect is playing a leading role in the sealing of the junction.

- Raise of the "effective thickness" of the flanges, which is caused by an increase of the thickness of the region between the bolt head and nut. This results in a better transmission of the load exerted by the bolts [14], which, in turn, produces a better distribution of the contact pressure. Indeed, Song and Moran [15] derived a simplified formula based on finite-element (FE) computations, which relates the radius of the nominal area of contact $\left(r_{c}\right)$ to the thickness of the connecting plates $\left(L_{P}\right)$ and the radius of the bolt head or washer $\left(B_{T}\right)$ when one single bolt is used to connect flat plates

$$
r_{c}=B_{T}+L_{P} / 2 .
$$

Extrapolating this simple rule to the flange under test, in order to have a good contact, the distance between screws should be less than $2 \cdot r_{c}$. For the flanges employed $(5-\mathrm{mm}$ thick) and the washers used (2.85-mm radius), the distance $2 \cdot r_{c}$ is equal to $10.7 \mathrm{~mm}$. In Fig. 3 , it is seen that the distance between screws in the broad wall is $13 \mathrm{~mm}$, whereas the distance between bolts in the narrow wall is $20 \mathrm{~mm}$. Thus, the flange design is not optimized regarding the rule 


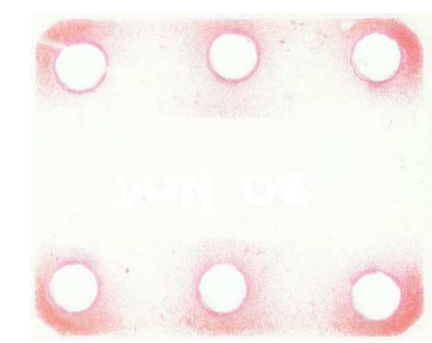

(a)
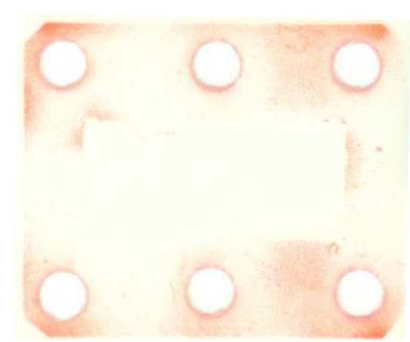

(b)
Fig. 7. (a) Seal for the case that no gasket is introduced. (b) Seal for the case that two flat gaskets are inserted.

given in (1). This is more critical in the narrow wall, although it is expected that, in this zone, a lower intermodulation level is generated since there is no electrical current flowing through the interface [16]. Of course, this is a rather simplified approach since a bolted connection with several screws requires a much more complex analysis (see the Appendix). However, it can be used as a guideline for a conservative flange design procedure.

Indeed, when two gaskets were added, $2 \cdot r_{c}$ was larger than $13 \mathrm{~mm}$ (it is around $13.7 \mathrm{~mm}$ ) and the intermodulation response was significantly improved [see Fig. 6(c)] due to the fact that the contact on the overall connection had been notably enhanced. To visualize this effect, thin sheets (which react under pressure by coloring themselves) were inserted between the flanges to check the quality of the contact at the junction. This is shown in Fig. 7 (the darker the sheet becomes, the better is the contact). It is seen that in the pure waveguide connection [see Fig. 7(a)], a very good contact was achieved only around the bolts. However, when two flat gaskets were inserted [see Fig. 7(b)], the contact was more spread on the whole surface. Moreover, the pressure at the narrow walls was clearly improved as well.

- Decrease of the surface deformation due to a lowering of the available force per interface, which is caused by the absorption of elastic energy in several junctions instead of one single connection. As a consequence, for the same applied mechanical load, a lower total pressure is available per interface and, thus, the small-scale surface deflection decreases. Hence, the intermodulation level must be increased due to the lack of formation of metal-to-metal contacts by contaminant layer breaking. This effect is also responsible for exciting high intermodulation levels at low torque ranges before the gasket(s) adapts(adapt) to the waveguide flanges. Indeed, at low torques, high electromagnetic radiation was detected flowing out of the flange when gaskets were used, exciting large and unstable intermodulation levels. In this situation, it was experimentally verified that the screws were strongly contributing to the intermodulation level due to the lack of seal of the junction.

To sum up, the addition of gaskets has the following two main opposite effects on the intermodulation response of the connection.

1) An increase of the intermodulation level due to the increment of the number of metallic connections and a decrease of the total applied pressure per interface.
2) A decrease of the intermodulation level caused by the increase of the area of contact due to the improvement of the elastic response of the connection and of the "effective flange thickness."

Therefore, depending on each particular situation, the insertion of gaskets can lead to an improvement of the intermodulation response of the system or to a further degradation. In this case, at nominal torque levels, the use of gaskets importantly improves the intermodulation performance of the connection. At low torque levels, however, the insertion of gaskets always leads to an increase of intermodulation caused by the lack of deformation of the metallic surfaces in contact.

The intermodulation behavior when bridged gaskets were inserted [see Fig. 6(b)] was, in principle, rather surprising as well. This combination presented the worst results (intermodulation level higher than $-110 \mathrm{dBm}$ at the highest torque). However, this configuration results in an important increase of the pressure in the RF path zone and, thus, an improvement in the intermodulation level would be expected, at least at high torques. Nevertheless, it was found by simple visual inspection that the surface of these gaskets was quite irregular, presenting many flaws and high-scale defects, which explains the high intermodulation levels measured.

Finally, it is remarkable that a displacement in the location of the intermodulation valley occurred after the use of the gaskets (see Fig. 6(d) compared to Fig. 5). This was caused by the plastic deformation of the waveguides close to the RF path region (by using the bridged samples), a higher force being necessary in order to join these flange regions when the contact was made again between the waveguides.

2) Silver-Plated Gaskets: Silver-plated Al gaskets were also inserted between the aluminum waveguides (see results in Fig. 8). It is expected that silver-plated connections present lower intermodulation levels than aluminum ones at metallic connections, as shown by previous researchers [7], [9]. On the other hand, it is important to notice that, since the base material was the same (aluminum), the "elasticity" of the gasketed junction remained basically unchanged. It was found that the insertion of such gaskets followed a similar behavior to the case of $\mathrm{Al}$ gaskets in the sense that very high intermodulation levels were detected at low torque levels, but a reduction in the high torque range was found. Nevertheless, no substantial improvement was observed with respect to the case of aluminum gaskets, except for the case of silver-plated bridged gaskets, which indicates that the mechanical effects were mainly dominating the overall intermodulation response. For the bridged gaskets case, the intermodulation level was driven around the noise floor $(-145 \mathrm{dBm})$ at high torques. This improvement was caused by the increase of contact around the waveguide cavity (RF current path zone) and the good intermodulation response of Ag.

The measurements performed after this set of measurements for the bare connection [see Fig. 8(d)] showed a further modification of its intermodulation response [by comparison to Fig. 6(d)], indicating a further surface flattening caused by the use of high-pressure gaskets. 


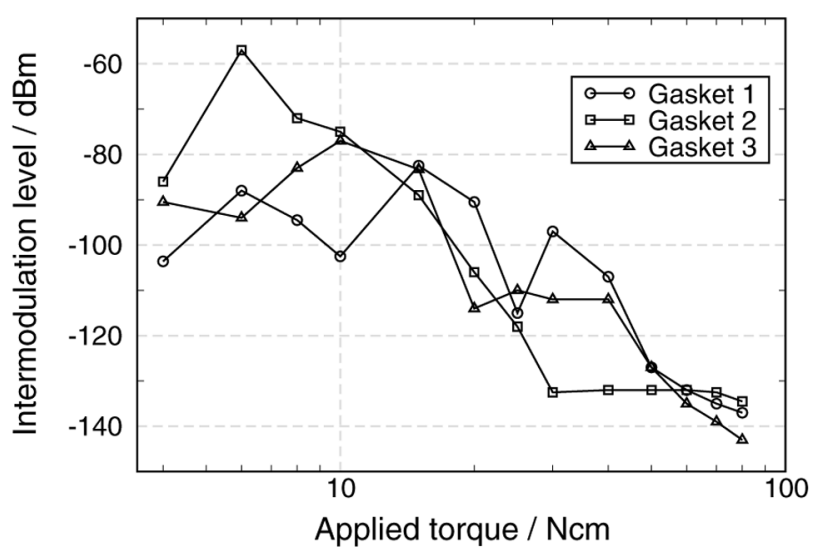

(a)

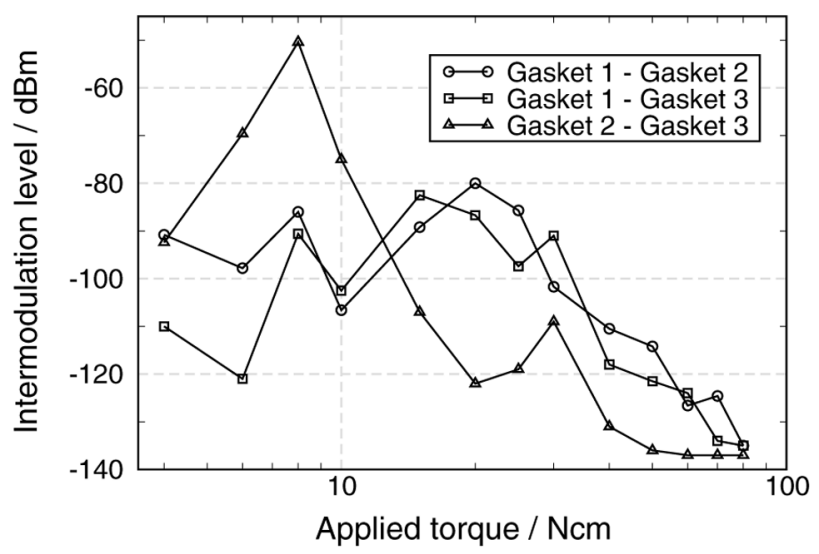

(c)

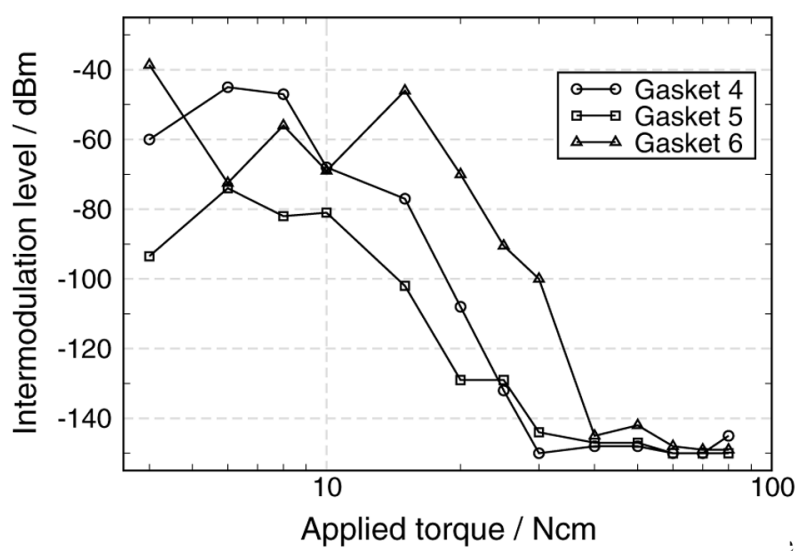

(b)

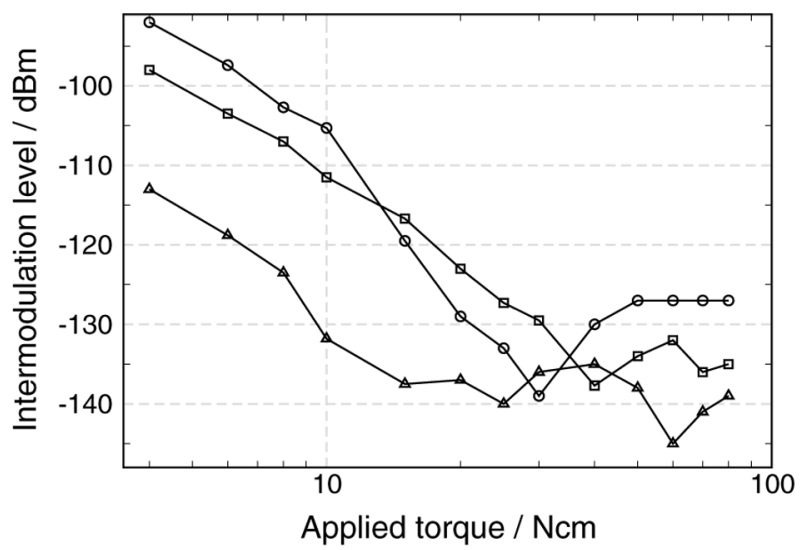

(d)

Fig. 8. Effect of inserting silver-plated aluminum gaskets at the connection between two rectangular aluminum waveguides. $P=60 \mathrm{~W}$. (a) Passive intermodulation level versus applied torque when one flat gasket is inserted. (b) Passive intermodulation level versus applied torque when one "bridged" gasket is inserted. (c) Passive intermodulation level versus applied torque when two flat gaskets are inserted. (d) Passive intermodulation level versus applied torque without gaskets after the insertion of silver-plated aluminum gaskets (three tests).

\section{B. Summary of Aluminum Waveguide Connections}

From the experimental results and analysis presented above, several conclusions can be extracted as follows.

1) At low loads, the use of gaskets results in rather high and unstable intermodulation levels. In fact, on many occasions, electromagnetic radiation flows out of the flange. At this point, the bolts themselves notably contribute to the measured intermodulation level.

2) The use of high-pressure gaskets changes the surface profile of the waveguide flanges in the RF path zone, as observed by the change in the intermodulation response after the series of tests.

3) The use of more than one gasket does not generally result in a worse intermodulation response at high torque values. The increase in the ability of the screws to transmit the applied torque positively compensates for the decrease of the surfaces deformation and the intermodulation generation caused by the increase in the number of metallic connections.

4) As a conservative baseline/guideline, flat flanges should be designed in such a way that the distance between screws is never larger than $2 \cdot r_{c}$, as defined in (1).

\section{Silver-Plated Aluminum WaVeguide Connections}

Here, passive intermodulation measurements on silver-plated aluminum flange bolted junctions are presented.

The first important fact that appeared when the waveguides were joined was that the full available input power $(170 \mathrm{~W}$ per carrier) was necessary in order to excite measurable intermodulation levels even for the lowest torque $(4 \mathrm{~N} / \mathrm{cm})$, demonstrating, as expected, that $\mathrm{Ag}$ connections are much better than aluminum junctions regarding their passive intermodulation performance. In other words, whereas a combined power of $60 \mathrm{~W}$ was enough in the case of aluminum to measure a significant intermodulation level even at high torques, this did not happen for silverplated waveguides.

Fig. 9 shows the intermodulation level as a function of the applied torque to the screws for the connection of two particular silver-plated waveguides. It is seen that the decrease of the intermodulation level with the applied torque was not as important as in the case of aluminum waveguides. In fact, the intermodulation level remained almost torque independent in the entire range.

More connections were tested in order to verify if this behavior was repeatable from connection to connection. An example is given in Fig. 10, which shows that, again, the inter- 


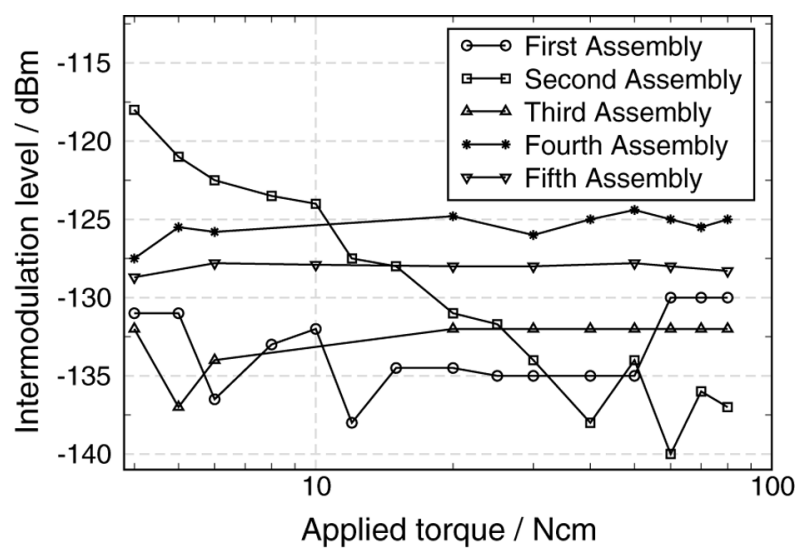

Fig. 9. Passive intermodulation level versus applied torque for a combination of two silver-plated aluminum waveguides. The measurements were repeated five times. $P=340 \mathrm{~W}$.

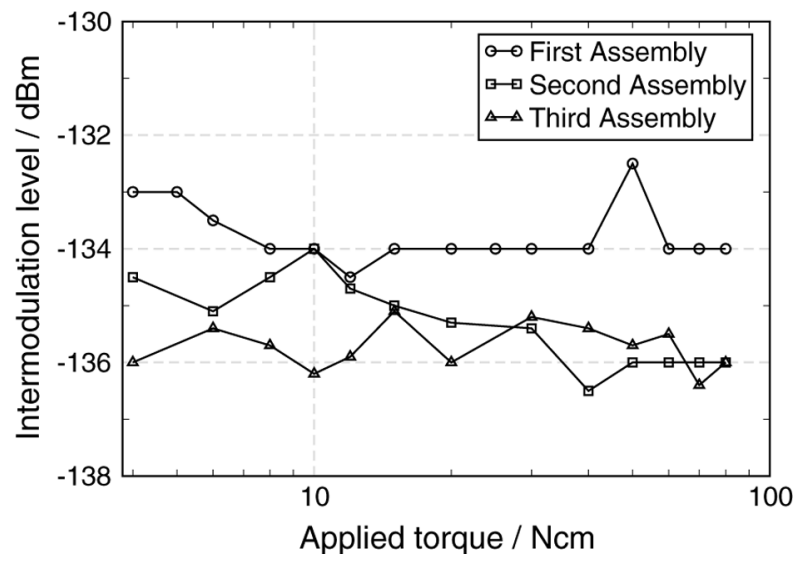

Fig. 10. Passive intermodulation level versus applied torque for a combination of two different (with respect to Fig. 9) silver-plated aluminum waveguides. The measurements were repeated three times. $P=340 \mathrm{~W}$.

modulation level kept more or less constant independent of the applied torque. This clear pattern can only be explained by the following three possibilities.

1) The measured intermodulation was not generated at the investigated interface, but in the flanges between the DUT and test setup.

2) The distortion was produced by the waveguides themselves and not by the junction.

3) The intermodulation level was originated at the expected interface, but a kind of saturation mechanism with respect to the applied torque was reached.

The first and second options are discarded because a gasket was introduced between the flanges showing that the intermodulation level could be driven below the noise floor (see below). Furthermore, the second possibility is even more unlikely since all the samples were manufactured by the same company (Tesat-Spacecom GmbH \& Co. KG, Backnang, Germany), following the same process as the rest of the components in the test setup. Hence, it is clear that the measured intermodulation was not generated at any other part of the system, but at the tested connection.

As a consequence, the only feasible explanation is related to the third point. It is possible that the connection quickly reaches a saturation level that cannot be improved by further tightening. However, this is suspicious because the rest of connections in the test setup were also silver-plated bolted junctions and a lower intermodulation level was achieved (noise floor). The difference between the tested interface and the other waveguide junctions that were forming the test setup in the critical zone (between the input and output diplexers, see Fig. 4) was that the latter were eight-hole flanges together with a high pressure (bridged) configuration. Such a configuration provides a better seal, which results in a lower intermodulation level. Moreover, these flanges have a distance between bolts always lower to $2 \cdot r_{c}$. As mentioned before, such a rule is not accomplished by the flanges under test.

On the other hand, Song and Moran [15] have also shown that the contact resistance (which is unequivocally related to the intermodulation response, see e.g., [16]) of bolted connections is basically torque and material independent and is directly related to (1) provided that the surfaces are clean enough (no contaminant layer or it can be disrupted easily). This is in complete agreement with the measured intermodulation level for these connections, which does not significantly vary with the applied torque.

\section{A. Gaskets}

As in the case of Al waveguides, both pure aluminum and silver-plated Al gaskets were inserted between the waveguide flanges in order to assess its impact in the intermodulation performance of the system. All the gaskets were inserted between the silver-plated Al waveguides whose intermodulation response is presented in Fig. 10. All the measurements were performed at a combined input power of $P=340 \mathrm{~W}$.

1) Aluminum Gaskets: Fig. 11 shows the measured data for these gaskets. Again, at the highest torque levels, the insertion of the gaskets did not result in a higher intermodulation level, except for the bridged gaskets (as in the case of aluminum waveguides). In fact, for the flat gasket case (one or two), the intermodulation level was lower than the pure waveguide connection. Such a behavior is rather surprising since it means that the silver waveguide connection could produce a higher intermodulation level than two silver-aluminum contacts if a gasket was used. Moreover, the results when two gaskets were employed were quite good considering that an $\mathrm{Al}-\mathrm{Al}$ connection was present. This is understood, again, by the increase of the seal of the junction caused by the increment of the "effective flange thickness," and shows that, in general, this improvement affects the intermodulation level to a much larger extent than the presence of additional metallic connections. After this set of measurements [see Fig. 11(d)], the intermodulation response of the waveguides was practically unaltered, indicating that, for Ag connections, the surface topography seems to be of secondary importance.

2) Silver-Plated Gaskets: As shown in Fig. 12, the insertion of silver-plated gaskets (flat or bridged) did not improve the intermodulation response of the system. In fact, exactly the same intermodulation level was measured (around $-135 \mathrm{dBm}$ ) at high torques. Even the use of bridged gaskets could not improve the intermodulation level. However, the use of two gaskets at once reduced the intermodulation level around the noise floor, evidencing that, in this case, the improvement on the ability of 


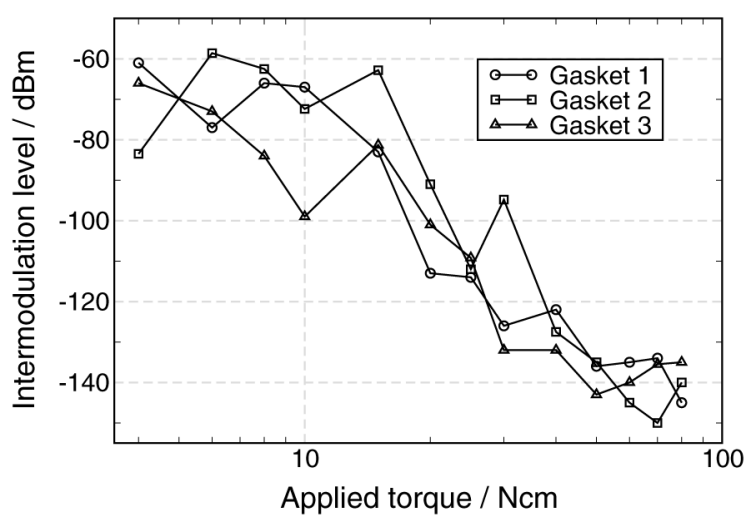

(a)

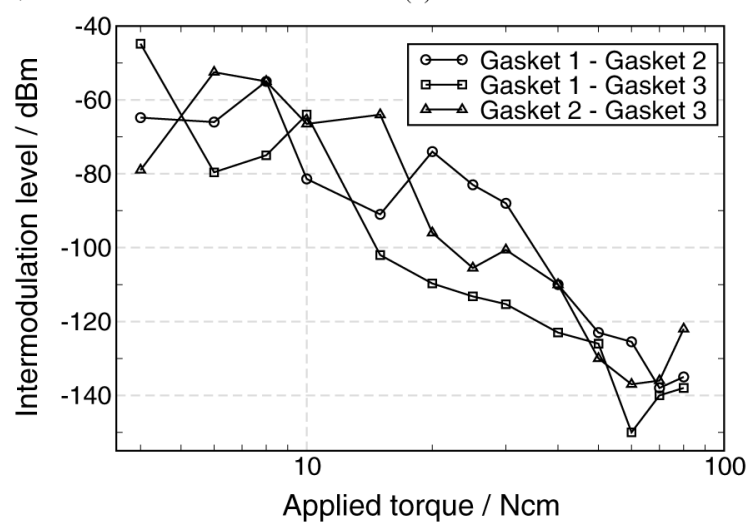

(c)

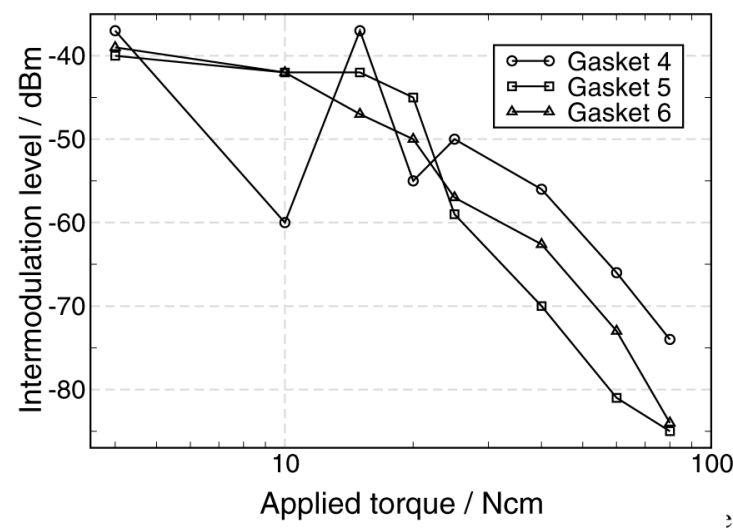

(b)

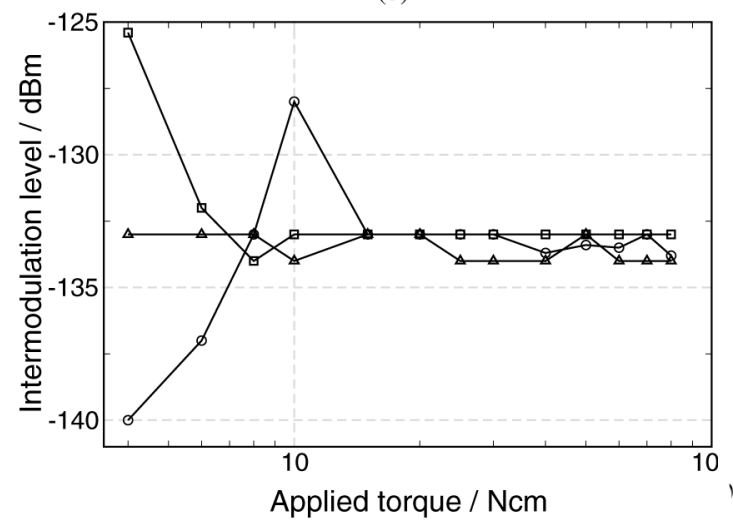

(d)

Fig. 11. Effect of inserting aluminum gaskets at the connection between two rectangular silver-plated aluminum waveguides. $P=340 \mathrm{~W}$. (a) Passive intermodulation level versus applied torque when one flat gasket is inserted. (b) Passive intermodulation level versus applied torque when one "bridged" gasket is inserted (c) Passive intermodulation level versus applied torque when two flat gaskets are inserted. (d) Passive intermodulation level versus applied torque without gaskets after the insertion of aluminum gaskets (three tests).

the screws to transmit the mechanical load is especially relevant for the reduction of the intermodulation level of bolted flange connections. Indeed, for silver-plated Al connections, the importance of reaching a contact pressure threshold on the whole surface becomes evident, being that this threshold is relatively low.

Finally, the intermodulation response of the silver-plated waveguide connection was not significantly changed due to the performance of these measurements [see Fig. 12(d)] suggesting, once more, that the surface aspect plays a secondary role.

\section{B. Summary of Silver-Plated Aluminum Waveguide Connections}

The following conclusions related to the intermodulation data for silver-plated connections can be extracted.

1) Silver-plated waveguides show, as expected, lower intermodulation levels than aluminum contacts. In fact, the intermodulation level generated can be detected thanks to the quality of the test setup employed.

2) The importance of reaching high pressures in such contacts is secondary. From a particular torque value, the intermodulation level becomes rather torque independent. It is by far more important to have a relatively low pressure-enough to form metal-to-metal contacts-but be evenly distributed.
3) The application of gaskets can improve the intermodulation performance of the connection, which confirms that the intermodulation lowering due to a better pressure distribution is more relevant than the intermodulation level rise caused by the increase in the number of metallic contacts.

4) The performance of the tests does not affect the intermodulation response of the waveguide connection significantly, which indicates that small-scale surface irregularities (roughness) are secondary for these connections.

5) As in the case of $\mathrm{Al}$ waveguides, the flanges should be designed in such a way that the distance between screws is never larger than $2 \cdot r_{c}$.

\section{CONCLUSION}

A systematic series of laboratory tests has been presented for the evaluation of intermodulation levels in waveguide flange bolted connections. Relevant results have been found for both aluminum and silver-plated aluminum connections. In particular, the relevance of reaching a high, but homogeneous pressure distribution at the flanges has been clearly addressed. The importance of proper flange design for the reduction of intermodulation levels with clean surfaces similar to those formed by silver connections has been noted as well. For this case, the advantage of a clever flange geometric design over torque 


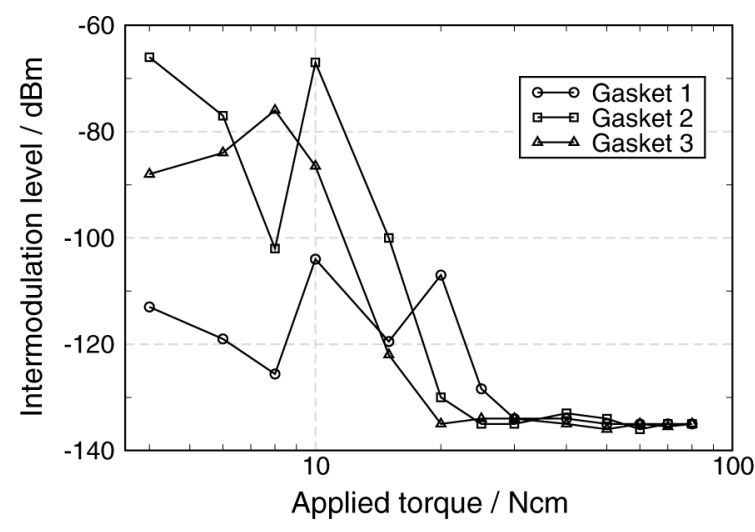

(a)

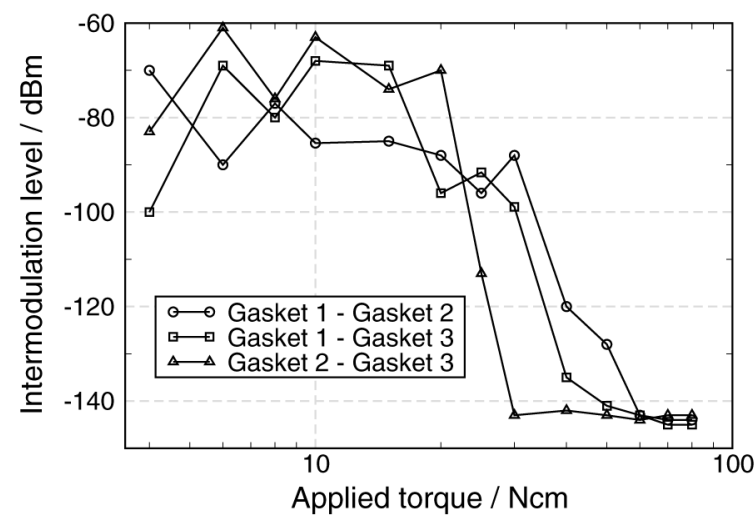

(c)

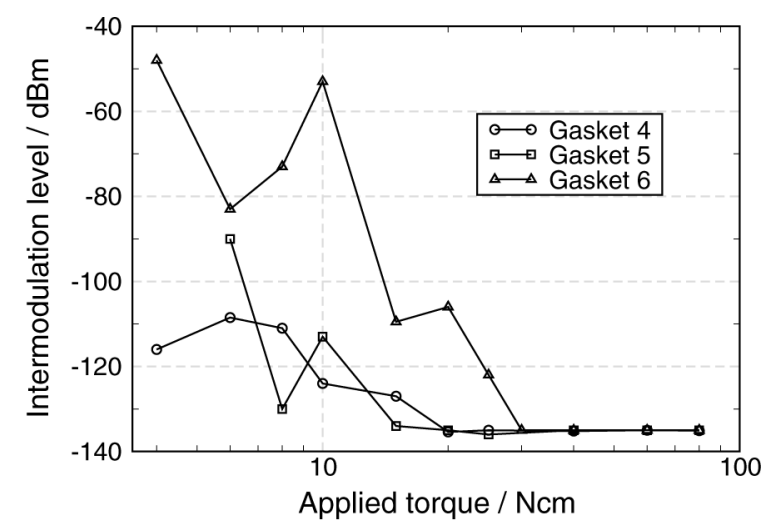

(b)

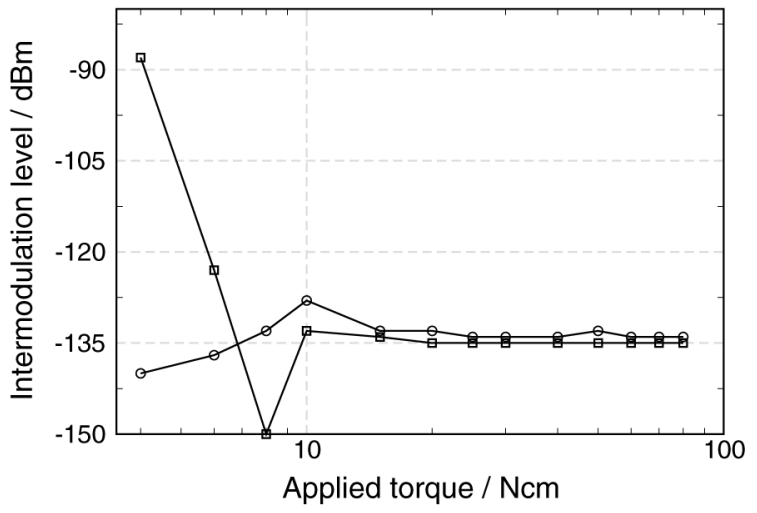

(d)

Fig. 12. Effect of inserting silver-plated aluminum gaskets at the connection between two rectangular silver-plated aluminum waveguides. $P=340 \mathrm{~W}$. (a) Passive intermodulation level versus applied torque when one flat gasket is inserted. (b) Passive intermodulation level versus applied torque when one "bridged" gasket is inserted. (c) Passive intermodulation level versus applied torque when two flat gaskets are inserted. (d) Passive intermodulation level versus applied torque without gaskets after the insertion of silver-plated aluminum gaskets (two tests).

levels applied and over small-scale surface irregularities has been demonstrated.

Future research should be focused on the study of the intermodulation response in terms of flange, gasket, and bolt thicknesses for a wide range of dimensions, including different frequency bands. Low-weight intermodulation-free flanges based on the test data acquired should be designed for practical satellite applications.

\section{APPENDIX}

\section{CONTACT PRESSURE EVALUATION}

An estimation of the contact pressure between the flanges can be easily performed. The resulting force $(F)$ is related to the applied torque to the bolts $\left(T_{B}\right)$ by

$$
F=\frac{T_{B}}{K \cdot D_{B}}
$$

where $K$ is the "nut factor" (with a typical value of 0.2 ) and $D_{B}$ is the diameter of the bolt or of the washer used (in this case, 2.85 $\mathrm{mm})$. The pressure is simply obtained using $P=(F) /\left(A_{n}\right)$, where $A_{n}$ is determined from the dimensions given in Fig. 3. For the flat case $A_{n} \approx 677 \mathrm{~mm}^{2}$ and for the bridged case, it is approximately $A_{n} \approx 186 \mathrm{~mm}^{2}$, and, thus, for an applied torque of, for instance, $95 \mathrm{~N} / \mathrm{cm}$ and since there are six screws, the pressure of contact is around $14.7 \cdot 10^{6} \mathrm{~Pa}\left(2130 \mathrm{lbf} / \mathrm{in}^{2}\right)$ for the flat case, and $53.7 \cdot 10^{6} \mathrm{~Pa}\left(7800 \mathrm{lbf} / \mathrm{in}^{2}\right)$ for the bridged flange. The space industry normally uses as a condition for intermodulation-free flanges a contact pressure of $10000 \mathrm{lbf} / \mathrm{in}^{2}\left(69 \cdot 10^{6} \mathrm{~Pa}\right)$, which indicates that even the high-pressure flange does not fulfill such a requirement in average.

However, this pressure is determined assuming that the force is uniformly applied on the whole surface. Obviously, this is far from the truth, and it is expected to have larger contact pressures close to the bolts and much lower far from them. In order to estimate this pressure distribution with accuracy, numerical methods for mechanical junctions have to be employed. An option is to use a commercial software in order to determine the pressure profile on the surface. For example, ANSYS, which is based on the FE method, is a very well-known software tool for such a purpose. A simulation with ANSYS is shown in Fig. 13 for the case of a bridged flange. It is found, as expected, that the pressure is extremely inhomogeneous. In fact, the requirement regarding the $69-\mathrm{N} / \mathrm{mm}^{2}$ contact pressure is only reached in very few places for this bridged configuration. Moreover, close to the inner hole of the waveguide, the contact pressure never exceeds $13 \mathrm{~N} / \mathrm{mm}^{2}$, whereas in the outer part of the inner bridge, the contact pressure can reach values around $120 \mathrm{~N} / \mathrm{mm}^{2}$ in the nearest points to the bolts. This indicates the difficulties to reach high 


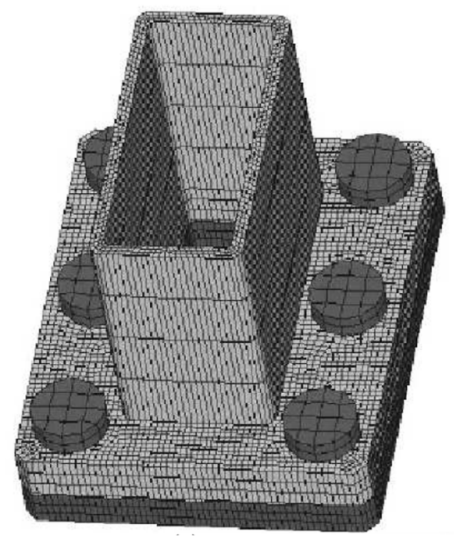

(a)

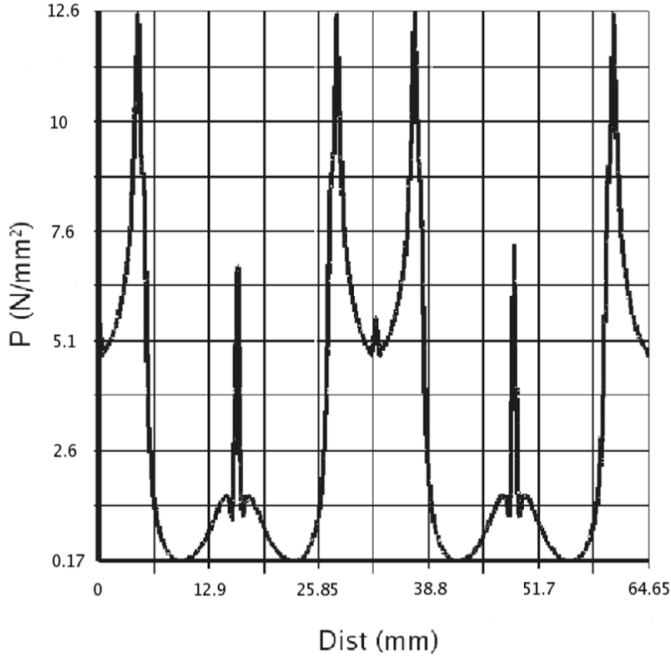

(d)

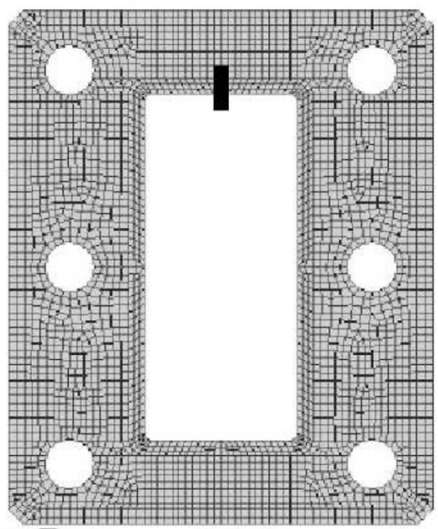

(b)

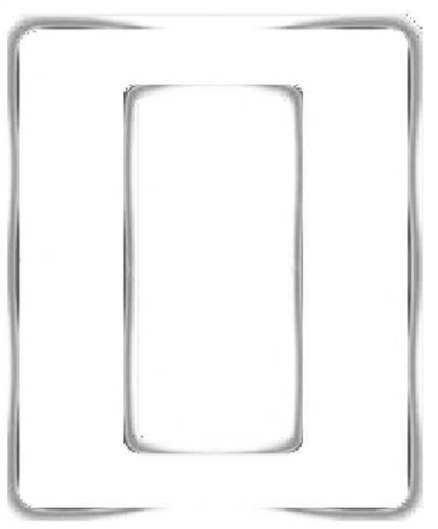

(c)

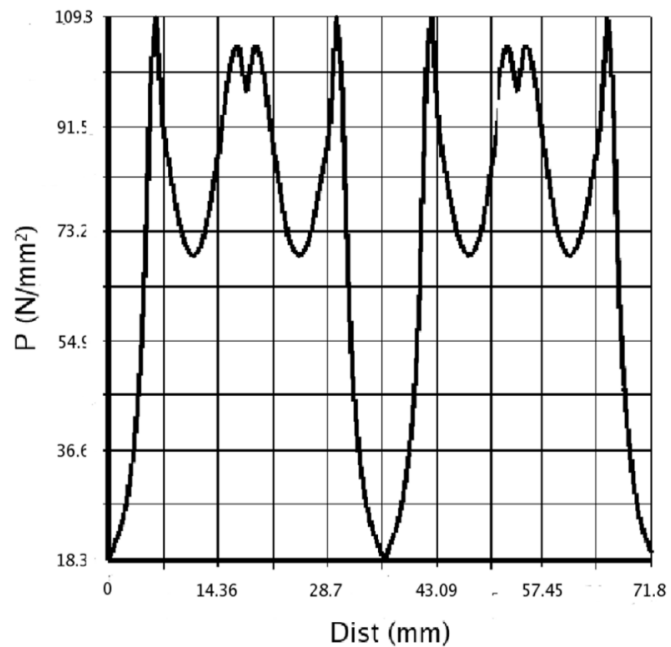

(e)

Fig. 13. Contact pressure estimation of a "bridged" connection using ANSYS. (d) and (e) "Dist" is the distance from the black mark in (b). (a) Geometry and 3-D mesh with ANSYS. (b) 2-D view of the mesh. (c) Qualitative contact pressure: the darker the region, the higher the pressure. (d) Contact pressure in the inner rim of the inner "bridge." (e) Contact pressure in the outer rim of the inner "bridge."

pressures, even with a high-pressure flange configuration close to the RF path zone.

\section{ACKNOWLEDGMENT}

The authors would like to thank Tesat-Spacecom GmbH \& Co. KG, Backnang, Germany, for the facilities provided in order to perform the measurements presented in this study.

\section{REFERENCES}

[1] P. L. Lui, "Passive Intermodulation interference in communication systems," Electron. Commun. Eng. J., pp. 109-118, Jun. 1990

[2] C. F. Hoeber, D. L. Pollard, and R. R. Nicholas, "Passive intermodulation product generation in high power comunications satellites," in 11th AIAA Commun. Satellite Syst. Conf., Mar. 1986, pp. 361-374.

[3] J. W. Boyhan, H. F. Lenzig, and C. Koduru, "Satellite passive intermodulation: Systems considerations," IEEE Trans. Aerosp. Electron. Syst., vol. 32, no. 2, pp. 1058-1064, Jul. 1996.

[4] A. P. Foord and A. D. Rawlings, "A study of passive intermodulation interference is space RF hardware," ESTEC, Noordwijk, The Netherlands, Final Rep., Contract 111036, , May 1992.

[5] J. V. Rootsey, "Intermodulation study (intermodulation products in satellite ground antennas)," Philco-Ford Corporation, Palo Alto, CA, Tech. Rep., Aug. 1973.

[6] R. D. Cox, "Measurement of waveguide component and joint mixing products in 6-GHz frequency diversity systems," IEEE Trans. Commun. Technol., vol. COM-18, no. 1, pp. 33-37, Feb. 1970.
[7] M. Bayrak and F. A. Benson, "Intermodulation products from nonlinearities in transmission lines and connectors at microwave frequencies," Proc. Inst. Elect. Eng., vol. 122, pp. 361-367, Apr. 1975.

[8] F. Arazm and F. A. Benson, "Nonlinearities in metal contacts at microwave frequencies," IEEE Trans. Electromagn. Compat., vol. EMC-3, no. 3, pp. 142-149, Aug. 1980.

[9] E. Weibel and U. Hügel, "Tests evaluate the influence of junctions on PIM," Microw. RF, pp. 70-80, 1998.

[10] R. H. Martin, "Nonlinearity in RF cables and connectors," ERA, Leatherhead, Surrey, U.K., ERA Rep. 2885, Apr. 1976.

[11] R. H. Martin and A. Williams, "Measurement of intermodulation products at UHF in aircraft related situations," ERA, Leatherhead, Surrey, U.K., ERA Rep. 3082, Sep. 1976.

[12] C. Vicente, D. Wolk, H. L. Hartnagel, and D. Raboso, "An experimental investigation on passive intermodulation at rectangular waveguide interfaces," in IEEE MTT-S Int. Microw. Symp. Dig., San Francisco, CA, Jun. 2006, pp. 242-245.

[13] J. H. Bickford, Gaskets and Gasketed Joints. New York: Marcel Dekker, 1997.

[14] S. Willibald, "Bolted connections for rectangular hollow sections under tensile loading," Ph.D. dissertation, Dept. Civil Eng., Geo-, Environ. Sci., Univ. Fridericiana zu Karlsruhe, Karlsruhe, Germany, 2003.

[15] S. Song and K. P. Moran, "Thermal and electrical resistances of bolted joints between plates of unequal thickness," in 9th Annu. IEEE Semiconduct. Thermal Meas. Management Symp., Feb. 1993, no. 4, pp. 28-34.

[16] C. Vicente and H. L. Hartnagel, "Passive-intermodulation analysis between rough rectangular waveguide flanges," IEEE Trans. Microw. Theory Tech., vol. 53, no. 8, pp. 2515-2525, Aug. 2005. 


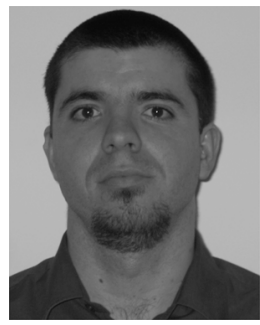

Carlos Vicente was born in Elche, Spain, in 1976. He received the Dipl. degree in physics from the University of Valencia, Valencia, Spain, in 1999, and the Ph.D. degree from Technical University of Darmstadt, Darmstadt, Germany, in 2005.

From 1999 to the beginning of 2001, he was a Research Assistant with the Department of Theoretical Physics, University of Valencia. Since 2005, he has been with the Department of Communications, Technical University of Valencia, Valencia, Spain. His research concerns the electromagnetic analysis and design of microwave passive components and its response in terms of power handling.

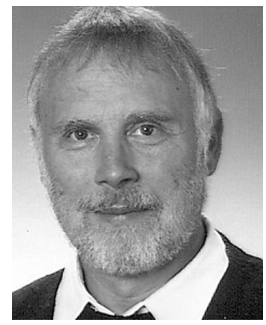

Dieter Wolk was born in Wilhelmshaven, Germany, in August 1948. He received the Dipl. Ing. degree in electrical engineering ( $R F$ technique) from the Technical University of Hannover, Hannover, Germany, in 1975.

He then joined the Radio Link Division, AEGTelefunken, Backnang, Germany, where he was involved in the development of solid-state power amplifiers [Gunn, IMPATT, field-effect transistor (FET)]. Since 1979, he has been with the Space Communications System Division, AEG-Telefunken (now Tesat Spececom GmbH \& Co. KG), Backnang, Germany, where he is currently a Senior Engineer involved with the Passive RF Equipment Division and engaged in research and development of advanced filters, multiplexers, and passive components for space application. His specialized research interest includes nonlinear effects in passive high-power devices (multipactor, corona, and passive intermodulation).

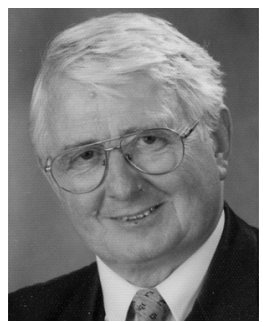

Hans L. Hartnagel (SM'72-F'92-LF'03) received the Dipl.-Ing. degree from the Technical University of Aachen, Aachen, Germany, in 1960, and the Ph.D. and Dr. Eng. degrees from the University of Sheffield, Sheffield, U.K., in 1964 and 1971, respectively.

In January 1971, he became a Professor of electronic engineering with the University of Newcastle-upon-Tyne, Newcastle-upon-Tyne, U.K. Since October 1978, he has been the Professor of High Frequency Electronics with the Technical University of Darmstadt, Darmstadt, Germany. He has held many consulting positions, partly while on temporary leave of absence from his university positions. He has authored several books and numerous scientific papers on microwave semiconductor devices, their technology, and circuits.

Prof. Hartnagel was the recipient of the 1990 Max-Planck-Prize, the 1994 Dr. h.c. presented by the University of Rome Tor Vergata, Rome, Italy, and the 1999 Dr. h.c. presented by the Technical University of Moldova, Moldova, Kishinev.

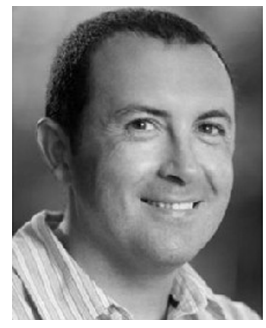

Benito Gimeno (M'01) was born in Valencia, Spain, on January 29, 1964. He received the Licenciado degree in physics and Ph.D. degree from the Universidad de Valencia, Valencia, Spain, in 1987 and 1992, respectively.

From 1987 to 1990 , he was a Fellow with the Universidad de Valencia. Since 1990, he has been an Assistant Professor with the Departamento de Física Aplicada y Electromagnetismo, Universidad de Valencia, where, in 1997, he became an Associate Professor. During 1994 and 1995, he was with the European Space Research and Technology Centre (ESTEC), European Space Agency (ESA), as a Research Fellow. In 2003, he was with the Università degli Studi di Pavia, Pavia, Italy, as a Visiting Scientist for a three-month period. His current research interests include computer-aided techniques for analysis of passive components for space applications, waveguides, and cavities including dielectric objects, electromagnetic-bandgap structures, frequency-selective surfaces, and nonlinear phenomena appearing in power microwave subsystems (multipactor and corona effects).

Dr. Gimeno was the recipient of a 2003 Spanish Government Fellowship.

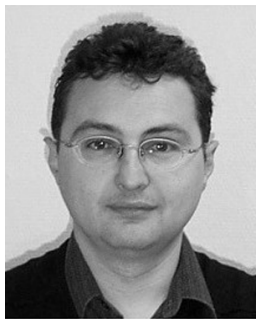

Vicente E. Boria (S'91-A'99-SM'02) was born in Valencia, Spain, on May 18, 1970. He received the Ingeniero de Telecomunicación degree (with first-class honors) and Doctor Ingeniero de Telecomunicación degree from the Universidad Politécnica de Valencia, Valencia, Spain, in 1993 and 1997, respectively.

In 1993, he joined the Departamento de Comunicaciones, Universidad Politécnica de Valencia, where since 2003 he has been a Full Professor. In 1995 and 1996, he was held a Spanish Trainee position with the European Space Research and Technology Centre (ESTEC)-European Space Agency (ESA), Noordwijk, The Netherlands, where he was involved in the area of electromagnetic (EM) analysis and design of passive waveguide devices. He has authored or coauthored five chapters in technical textbooks, 40 papers in refereed international technical journals, and over 100 papers in international conference proceedings. His current research interests include numerical methods for the analysis of waveguide and scattering structures, automated design of waveguide components, radiating systems, measurement techniques, and power effects (multipactor and corona) in waveguide systems.

Dr. Boria is a member of the IEEE Microwave Theory and Techniques Society (IEEE MTT-S) and the IEEE Antennas and Propagation Society (IEEE AP-S) since 1992. He serves on the Editorial Boards of the IEEE TRANSACTIONS ON MicROWAVE THEORY AND TECHNIQUES and IEEE MICROWAVE AND WIRELESS COMPONENTS LETTERS. He is also a member of the Technical Committees of the IEEE MTT-S International Microwave Symposium (IMS) and of the European Microwave Conference. He was the recipient of the 2001 Social Council of Universidad Politécnica de Valencia First Research Prize for his outstanding activity during 1995-2000.

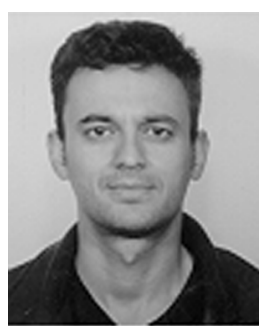

David Raboso was born in Alcázar De San Juan, Spain, in 1967. He studied at the Instituto Cervantes, Madrid, Spain. He received the M.S. degree in physics from the University Autonoma, Madrid, Spain, in 1992.

In 1992, he joined the European Space Research and Technology Centre (ESTEC), the main Research Center of the European Space Agency (ESA), Noordwijk, The Netherlands. Since then, he has been deeply involved in all European space programs where RF breakdown was considered a potential threat to the success of the mission. He is the contact point of all research activities at ESA in the field of multipactor, corona, and passive intermodulation, including the organization of the only international workshop dedicated to these issues, MULCOPIM. 